\title{
COMPARING TWO SUPPLIERS OF ALUMINIUM ALLOYS FOR FOUNDRY
}

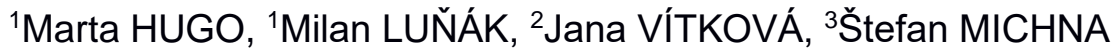 \\ ${ }^{1} B E N E S ̌$ a LÁT, a. s., Pořičany, Czech Republic, EU, marta.hugo@benesalat.cz, milan.lunak@benesalat.cz \\ ${ }^{2}$ KOVOLIS HEDVIKOV, a. s., Tremošnice, Czech Republic, EU, j.vitkova@kovolis-hedvikov.cz \\ 3Univerzita J. E. Purkyně v Ústí nad Labem, Czech Republic, EU, stefan.michna@ujep.cz
}

https://doi.org/10.37904/metal.2020.3593

\begin{abstract}
In this time many suppliers are existed with raw material for foundry and the same as a minimum number has difficult task of choosing the most suitable one. How we can search the best of them for us? It is hard question. This article shows what can be checking around the raw material. The basic test is spectral analysis, what is indispensable every foundry in this time. Chemical composition absolutely does not show an important information about properties of alloy. A little bit more tests were made for compare 2 suppliers. There were used measuring as Dichte Index, Thermal analysis and metallographic cuts as necessary evidence for proper evaluation.
\end{abstract}

Keywords: Ingot, metallographic cut, input inspection, aluminum alloy

\section{INTRODUCTION}

The company BENEŠ a LÁT a.s. (B\&L) has a number of casting technology. One factory is foundry with focus on preparation of the melt for the production of gravity and low pressure die cast aluminum castings. Al-Si alloys are used almost exclusively here. Alloy AISi7Mg0.3 was selected for this comparing 2 different suppliers. One of supplier No. 1 was new (cheaper) for foundry, because supplier No. 2 was checked more consistently. Alloy is typical for low pressure die casting technology. Visible differences between suppliers were in dimensions of ingots. Supplier No. 2 has dimension $600 \times 50 \times 45 \mathrm{~mm}$ and the supplier No. 1 has dimension $500 \times 50 \times 45 \mathrm{~mm}$. Smaller ingots had better using for workers at melting shop and here is expected lower risk for damage of melting furnace (especially crucible) during input of ingots.

\section{CHEMICAL COMPOSITION}

Foundry set up range of chemical composition for produce conditions. Basic standard for chemical composition is ČSN EN 1676. B\&L has special requirement on volume of some chemical elements. Comparing standard and requirement B\&L showed Table 1.

Table 1 Chemical composition by standard and B\&L requirement ( $w t \%)$

\begin{tabular}{|l|c|c|c|c|c|c|c|c|c|c|}
\hline Standard & $\mathbf{S i}$ & $\mathbf{F e}$ & $\mathbf{C u}$ & $\mathbf{M n}$ & $\mathbf{M g}$ & $\mathbf{Z n}$ & $\mathbf{T i}$ & other/all & other/together & $\mathbf{A l}$ \\
\hline ČSN EN 1676 & $6.5-7.5$ & 0.15 & 0.03 & 0.1 & $0.3-0.45$ & 0.07 & 0.18 & 0.03 & 0.1 & residual \\
\hline B\&L & $6.5-7.5$ & 0.15 & 0.03 & 0.1 & $0.3-0.45$ & 0.07 & $0.15-0.18$ & - & - & residual \\
\hline
\end{tabular}

Maximum limit of iron is selected for safety reasons. Production technology is used to iron mold and other iron tools, what could be contamination of melt and next reason is well known fact that higher content of iron could create unwanted intermetallic phases with negative effect on the mechanical properties and corrosion resistance of castings. Low and high limit of titanium is required for possible cost savings in subsequent or 
inoculation of the alloy. The aim of foundry production is to add $\mathrm{Ti}$ as little as possible before the melt is cast from holding furnace into the mould. Other/all means maximum content one from other elements, which do not mention in the table. Other/together means maximum total content other/all elements which do not mention in the table.

\subsection{Difference in chemical composition}

Minor deviations in Table 2 were during inspection measuring in B\&L with supplier's atests. The light red color showed range of limits of elements. Deviations are marked in deep red color. Supplier No. 1 had high value of $\mathrm{Li}$ in her atest. Value could be caused to mistake in record. Because inspection of delivery showed, that value of $\mathrm{Li}$ is suitable.

Table 2 Chemical composition during inspection ingots (wt\%)

\begin{tabular}{|c|c|c|c|c|c|c|c|c|c|c|c|c|c|}
\hline \multicolumn{14}{|c|}{ Chemical composition (wt.\%) } \\
\hline \multirow{3}{*}{ Supplier } & Sample & Si & $\mathrm{Fe}$ & $\mathrm{Cu}$ & $\mathrm{Mn}$ & $\mathrm{Mg}$ & $\mathrm{Zn}$ & $\mathrm{Ti}$ & $\mathrm{Sb}$ & $\mathrm{Li}$ & $\mathrm{Bi}$ & $P$ & $\mathrm{Ca}$ \\
\hline & $\min$. & 6.5 & 0 & 0 & 0 & 0.3 & 0 & 0.1 & 0 & 0 & 0 & 0 & 0 \\
\hline & $\max$. & 7.5 & 0.15 & 0.03 & 0.1 & 0.45 & 0.07 & 0.18 & 0.002 & 0.0005 & 0.004 & 0.004 & 0.004 \\
\hline \multirow{2}{*}{ No. 1} & Atest 1994 & 7.100 & 0.110 & 0.0100 & 0.0100 & 0.360 & 0.0053 & 0.135 & 0.0002 & 0.0390 & 0.000 & 0.0006 & 0.0000 \\
\hline & Inspection 1994 & 6.773 & 0.127 & 0.0002 & 0.0022 & 0.371 & 0.0004 & 0.130 & 0.0007 & 0.0001 & 0.001 & 0.0008 & 0.0007 \\
\hline \multirow{4}{*}{ №. 2} & Atest 781 & 7.210 & 0.100 & 0.0080 & 0.0080 & 0.380 & 0.0060 & 0.110 & 0.0001 & 0.0000 & 0.000 & 0.0006 & 0.0011 \\
\hline & Atest 801 & 7.020 & 0.120 & 0.0300 & 0.0600 & 0.380 & 0.0090 & 0.120 & 0.0003 & 0.0000 & 0.000 & 0.0005 & 0.0006 \\
\hline & Inspection 781 & 7.615 & 0.106 & 0.0087 & 0.0082 & 0.392 & 0.0073 & 0.127 & 0.0001 & 0.0001 & 0.0011 & 0.0005 & 0.0009 \\
\hline & Inspection 801 & 7.197 & 0.104 & 0.0240 & 0.0550 & 0.345 & 0.0089 & 0.147 & 0.0001 & 0.0001 & 0.001 & 0.0004 & 0.0004 \\
\hline
\end{tabular}

During measuring was big range in contain of $\mathrm{Si}$ and average from a few measurements was over to limit. The big range of content of $\mathrm{Si}$ was caused to inhomogeneity structure in case supplier No.2. But alloy had suitable chemical composition after remelting. And there was not detected any difference or difficulties after remelting, but may be it is about quite limited possibilities of detection of inclusions in B\&L foundry. Generally entry inspections are admited only alloys with correct chemical composition. In these cases entry inspection made except. Current supplier had minor deviation, which did not confirm during checking in B\&L. One of supply from new supplier had up to upper limit content of silicon. This supply was in testing and was checked all produce.

\section{SAMPLING OF METALLOGRAPHIC CUTS}

Samples for metallographic cuts were removed from one ingot of each specific supply. Place for cutting was defined in 3 parts of ingot. In total 3 samples were from ingot. In the Figure 1 you can see ingot has marked parts for samples. The first cutting started $50 \mathrm{~mm}$ from edge. The second cutting was in the middle of ingot and the thirth cutting is $50 \mathrm{~mm}$ from the second edge. Widths of samples

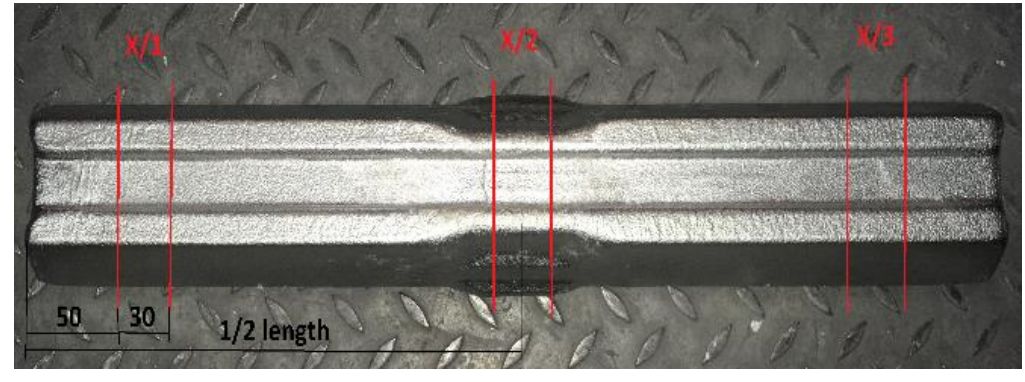

Figure 1 Cutting position of samples were $30 \mathrm{~mm}$. It was same for shorter ingot too. Of course for direct comparison.

All samples were checked on chemical composition from one side and other side was intended for grinding which is necessary condition as preparation before to create metallographic cut. Chemical compositions are showed Table 3. Samples for microsections were searched according to chemical compositions. 
Table 3 Chemical composition samples for grinding

\begin{tabular}{|c|c|c|c|c|c|c|c|c|c|c|c|c|}
\hline \multirow{2}{*}{ Samples } & \multicolumn{12}{|c|}{ Chemical composition (wt.\%) } \\
\hline & $\mathrm{Si}$ & $\mathrm{Fe}$ & $\mathrm{Cu}$ & $\mathrm{Mn}$ & $\mathrm{Mg}$ & $\mathrm{Zn}$ & $\mathrm{Ti}$ & $\mathrm{Sb}$ & Li & $\mathrm{Bi}$ & $P$ & $\mathrm{Ca}$ \\
\hline $781 / 1$ & 7.119 & 0.096 & 0.0055 & 0.0077 & 0.343 & 0.0055 & 0.115 & $<0.0070$ & $<0.0001$ & $<0.0010$ & $<0.0008$ & $<0.00005$ \\
\hline $801 / 1$ & 6.853 & 0.118 & 0.0200 & 0.0610 & 0.352 & 0.0085 & 0.121 & $<0.0070$ & $<0.0001$ & $<0.0010$ & $<0.0008$ & $<0.00005$ \\
\hline L1988/1 & 6.790 & 0.110 & $<0.0002$ & 0.0024 & 0.363 & 0.0046 & 0.156 & $<0.0070$ & 0.0001 & $<0.0010$ & $<0.0008$ & $<0.00005$ \\
\hline $781 / 2$ & 7.157 & 0.097 & 0.0055 & 0.0075 & 0.342 & 0.0054 & 0.116 & $<0.0070$ & $<0.00010$ & $<0.0010$ & $<0.0008$ & $<0.00005$ \\
\hline $801 / 2$ & 6.789 & 0.125 & 0.0220 & 0.0630 & 0.368 & 0.0090 & 0.124 & $<0.0070$ & $<0.00010$ & $<0.0010$ & $<0.0008$ & $<0.00005$ \\
\hline L1988/2 & 6.783 & 0.100 & $<0.0002$ & 0.0023 & 0.348 & 0.0042 & 0.155 & $<0.0070$ & $<0.00010$ & $<0.0010$ & $<0.0008$ & $<0.00005$ \\
\hline $781 / 3$ & 6.963 & 0.095 & 0.0055 & 0.0076 & 0.336 & 0.0051 & 0.115 & $<0.0070$ & $<0.00010$ & $<0.0010$ & $<0.0008$ & $<0.00005$ \\
\hline $801 / 3$ & 6.759 & 0.123 & 0.0210 & 0.0630 & 0.365 & 0.0087 & 0.122 & $<0.0070$ & $<0.00010$ & $<0.0010$ & $<0.0008$ & $<0.00005$ \\
\hline L1988/3 & 6.963 & 0.108 & $<0.0002$ & 0.0024 & 0.365 & 0.0045 & 0.15 & $<0.0070$ & $<0.00010$ & $<0.0010$ & $<0.0008$ & $<0.00005$ \\
\hline
\end{tabular}

All samples had satisfactory contain of all elements with standard. From first ingot were sent to metallographic analysis all 3 parts of ingot (781). Only one part from each ingot was sent from the second ingot (801) and ingot from supplier no. 1(L1988) as well.

\subsection{Metallographic cuts of all sample batches}

This rubric solved only samples 781/1, 801/1 (supplier No. 2) and sample L1988/1 (supplier no. 1). All samples had dendritic structures (in figures appearing as light white places). The finest structure in Figure 2 had sample $781 / 1$.
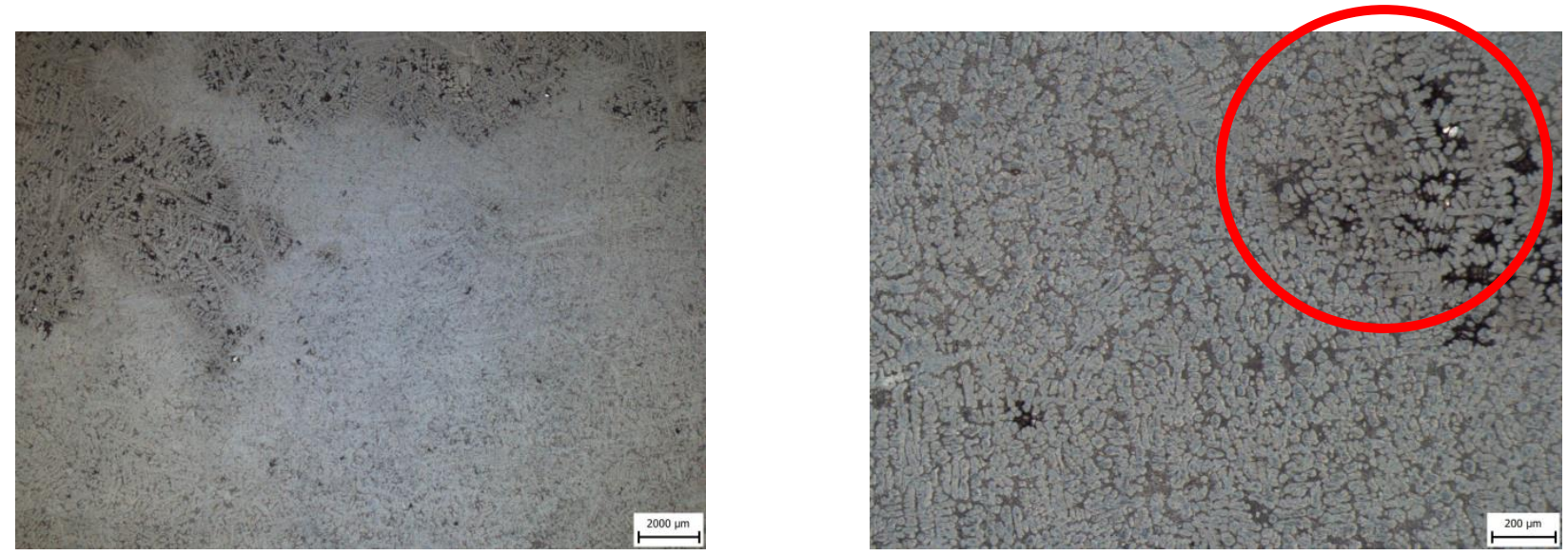

Figure 2 Sample $781 / 1$

The biggest size of dendrites in Figure 3 had structure sample 801/1. Sample 781/1 had visible areas with shrinkages in the group (marked in right figure).
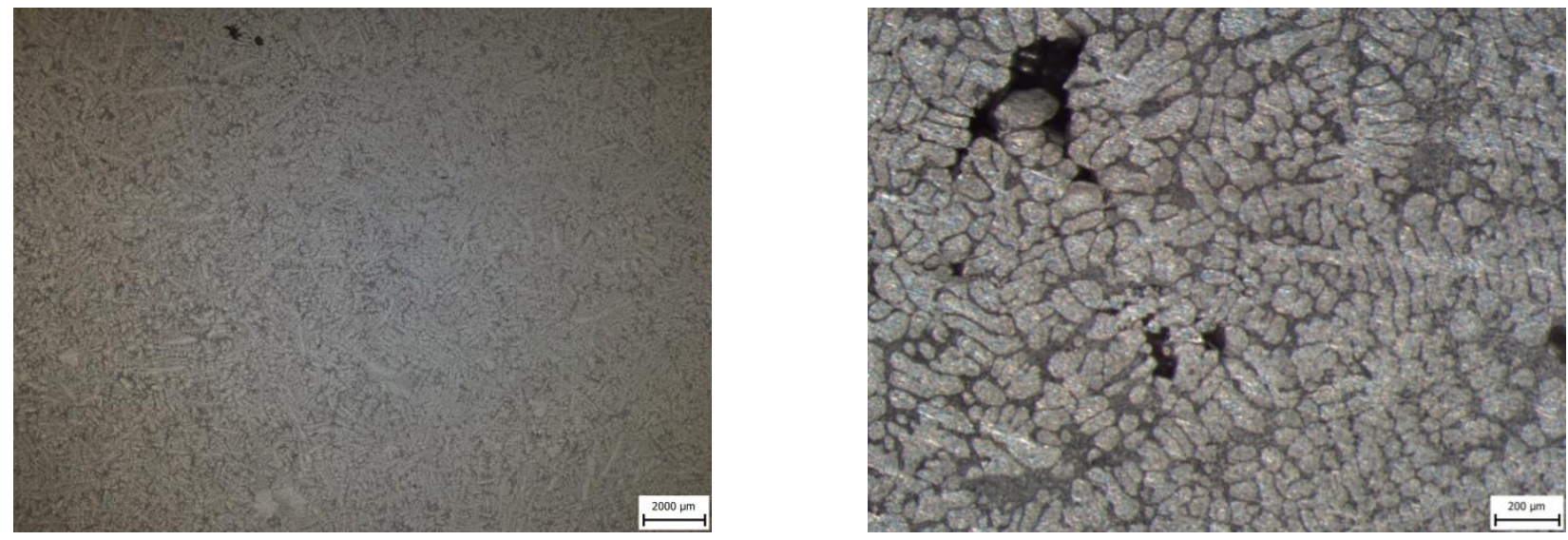

Figure 3 Sample 801/1 
The sample L1988/1 in Figure 4 had individually small shrinkages over entire surface of the cut. Shrinkages are not created to the group. This is proved that supplier no. 1 had more homogeneity material in this supply batch.
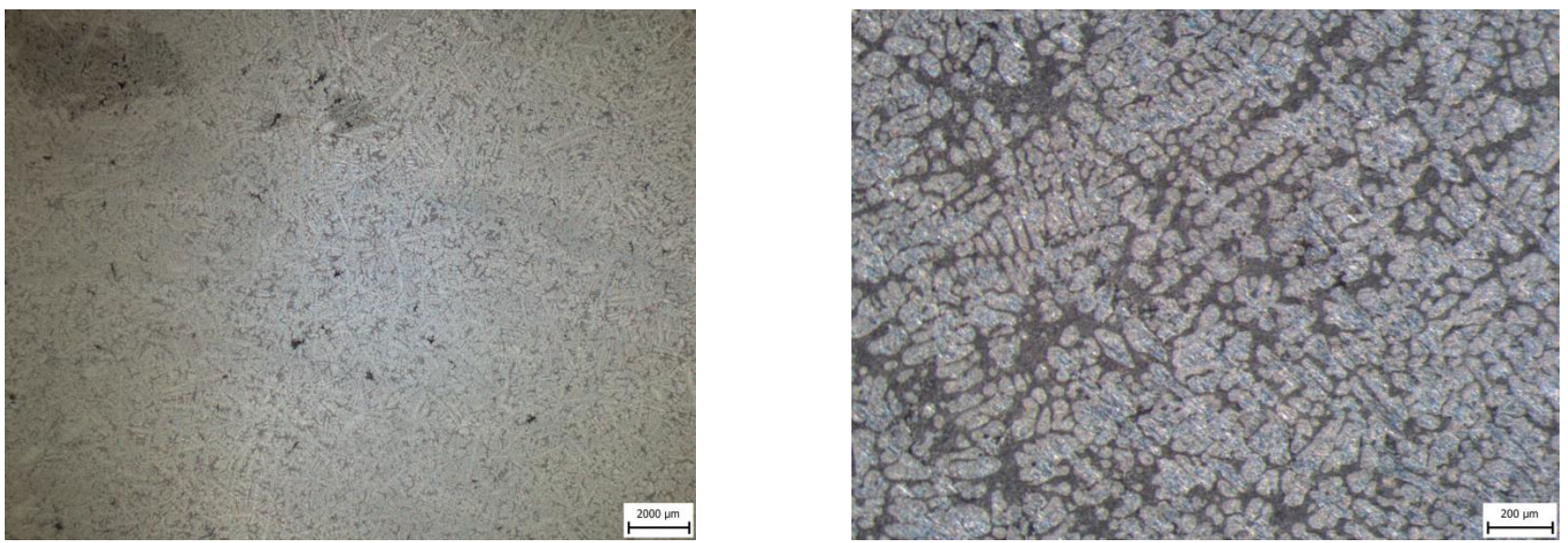

Figure 4 Sample 1988/1

\section{MELTING, DEGASSING, MEASURING DENSITY (DICHTE INDEX) AND TESTING BY THERMAL ANALYSIS}

Melting was carried out standard process in gas melting crucible furnaces. The contribution was $70 \%$ ingots and $30 \%$ scrabs. The melting temperature was $750{ }^{\circ} \mathrm{C} \pm 10{ }^{\circ} \mathrm{C}$. Melt degassing was performed at FDU (Foundry degassing unit with nitrogen as inert gas) device with standard program (cycle time is about 5 min) as all production of castings.

In the Figure 5 you can see degassing process in B\&L. The Dichte Index measurement was after degassing from transport pot. A sample for thermal analysis was taken from the transport pot too. Informations from thermal analysis are visible in the Figure 6.

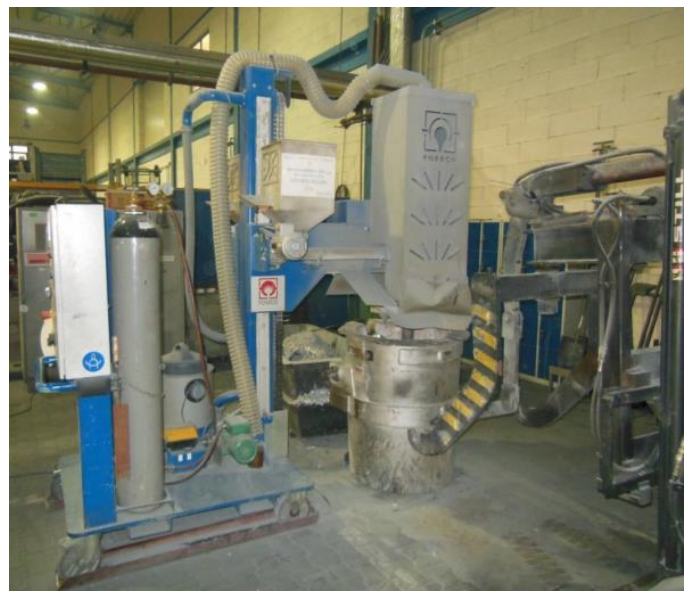

Figure 5 Degassing process

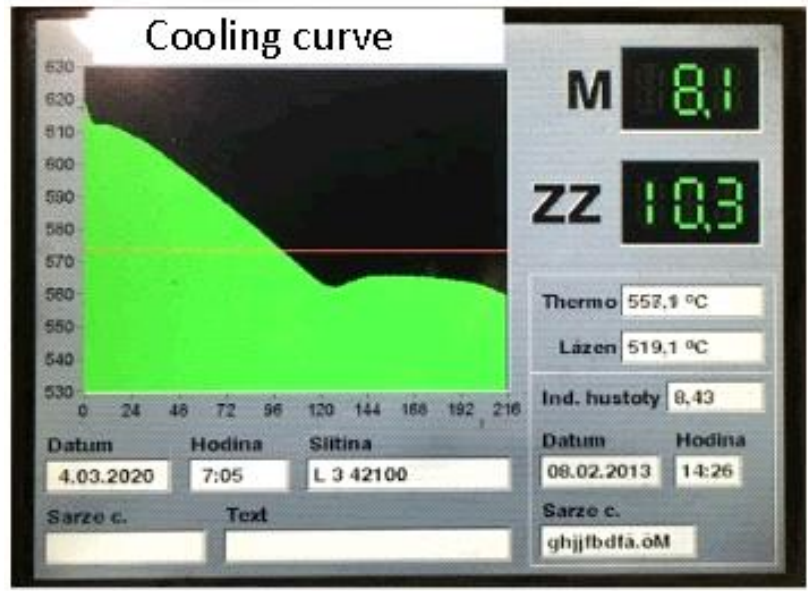

Figure 6 Cooling curve from thermal analysis

Date, hour and type of alloy are under curve. $M$ means value of modification and $Z Z$ means value of grain refinement. Typical values $M$ are in the range 6-15 and typical values $Z Z$ are in the range 8-15. Other information are about temperatures in crucible during measuring and the first measuring - date, hour and density index. Data for compare suppliers you can see in Table $\mathbf{4}$ and Table $\mathbf{5}$. 
Table 4 Supplier No. 1

\begin{tabular}{|c|c|c|c|c|c|c|c|c|c|c|c|c|}
\hline \multirow{2}{*}{ Date } & \multicolumn{9}{|c|}{ Chemical composition (wt.\%) } & \multirow{2}{*}{ DI } & \multicolumn{2}{|c|}{ Thermal analysis } \\
\hline & $\mathrm{Si}$ & $\mathrm{Fe}$ & $\mathrm{Cu}$ & $\mathrm{Mg}$ & $\mathrm{Ti}$ & $\mathrm{Ca}$ & $\mathrm{Pb}$ & $\mathrm{Sr}$ & $P$ & & Modificaton (-) & Grain refinement (-) \\
\hline 04.02 .2020 & 7.276 & 0.111 & 0.0014 & 0.33 & 0.116 & 0.0013 & 0.0008 & 0.006 & 0.0008 & 0.75 & 6.7 & - \\
\hline 05.02 .2020 & 6.903 & 0.126 & 0.0036 & 0.338 & 0.126 & 0.001 & 0.0008 & 0.0034 & 0.0008 & 0.75 & 8.0 & 13 \\
\hline 06.02 .2020 & 7.381 & 0.168 & 0.0078 & 0.314 & 0.125 & 0.001 & 0.0013 & 0.0081 & 0.0008 & 0.00 & 7.9 & 13 \\
\hline 07.02 .2020 & 7.381 & 0.168 & 0.0078 & 0.314 & 0.125 & 0.001 & 0.0013 & 0.0081 & 0.0008 & 0.38 & 7.5 & 13 \\
\hline 10.02 .2020 & 7.336 & 0.114 & 0.0014 & 0.321 & 0.127 & 0.0013 & 0.0008 & 0.004 & 0.0008 & 0.38 & 9.1 & - \\
\hline 11.02 .2020 & 7.147 & 0.108 & 0.0015 & 0.341 & 0.114 & 0.0011 & 0.001 & 0.0035 & 0.0008 & 0.38 & 8.9 & - \\
\hline 12.02 .2020 & 7.392 & 0.124 & 0.0034 & 0.315 & 0.133 & 0.0011 & 0.0008 & 0.0075 & 0.0008 & 0.38 & 7.6 & - \\
\hline$\varnothing$ & 7.259 & 0.131 & 0.0038 & 0.324 & 0.124 & 0.0011 & 0.0009 & 0.0058 & 0.0008 & 0.43 & 7.9 & 13 \\
\hline
\end{tabular}

Table 5 Supplier No.2

\begin{tabular}{|c|c|c|c|c|c|c|c|c|c|c|c|c|}
\hline \multirow{2}{*}{ Date } & \multicolumn{9}{|c|}{ Chemical composition (wt.\%) } & \multirow{2}{*}{$\mathrm{DI}$} & \multicolumn{2}{|c|}{ Thermal analysis } \\
\hline & $\mathrm{Si}$ & $\mathrm{Fe}$ & $\mathrm{Cu}$ & $\mathrm{Mg}$ & Ti & $\mathrm{Ca}$ & $\mathrm{Pb}$ & $\mathrm{Sr}$ & $P$ & & Modification (-) & Grain refinement (-) \\
\hline 03.12 .2019 & 7.191 & 0.105 & 0.0070 & 0.361 & 0.127 & 0.00005 & 0.0008 & 0.0035 & 0.0008 & 0.75 & 9.4 & 13.0 \\
\hline 04.12 .2019 & 7.175 & 0.103 & 0.0077 & 0.362 & 0.125 & 0.00005 & 0.0008 & 0.0021 & 0.0008 & 0.75 & 6.7 & 12.7 \\
\hline 05.12 .2019 & 7.267 & 0.102 & 0.0078 & 0.358 & 0.115 & 0.00005 & 0.0008 & 0.0036 & 0.0008 & 0.75 & 9.2 & 10.8 \\
\hline 06.12 .2019 & 7.16 & 0.102 & 0.0079 & 0.352 & 0.116 & 0.00005 & 0.0008 & 0.0037 & 0.0008 & 0.38 & 8,0 & 13.0 \\
\hline 09.12 .2019 & 6.971 & 0.100 & 0.0056 & 0.341 & 0.125 & 0.00005 & 0.0008 & 0.0029 & 0.0008 & 0.75 & 8.9 & 13.0 \\
\hline 10.12 .2019 & 7.098 & 0.098 & 0.0065 & 0.351 & 0.124 & 0.00005 & 0.0008 & 0.0021 & 0.0008 & 0.75 & 7.6 & 13.0 \\
\hline 11.12 .2019 & 6.784 & 0.101 & 0.0091 & 0.383 & 0.117 & 0.00005 & 0.0008 & 0.0044 & 0.0008 & 0.75 & 9.6 & 12.4 \\
\hline$\varnothing$ & 7.092 & 0.102 & 0.0074 & 0.358 & 0.121 & 0.00005 & 0.0008 & 0.0031 & 0.0008 & 0.70 & 8.5 & 12.5 \\
\hline 12.12 .2019 & 7.005 & 0.112 & 0.0089 & 0.368 & 0.123 & 0.00005 & 0.0008 & 0.0029 & 0.0008 & 0.75 & 7.8 & 12.6 \\
\hline 13.12 .2019 & 7.024 & 0.114 & 0.0110 & 0.384 & 0.128 & 0.00300 & 0.0008 & 0.0054 & 0.0008 & 1.51 & - & - \\
\hline 06.01 .2020 & 6.917 & 0.171 & 0.0087 & 0.328 & 0.138 & 0.00008 & 0.0008 & 0.0081 & 0.0008 & 0.38 & 3.7 & 13,0 \\
\hline 07.01 .2020 & 6.958 & 0.175 & 0.0130 & 0.325 & 0.144 & 0.00005 & 0.0009 & 0.0056 & 0.0036 & 0.38 & - & - \\
\hline 08.01 .2020 & 6.882 & 0.104 & 0.0160 & 0.340 & 0.134 & 0.00005 & 0.0008 & 0.0045 & 0.0008 & 0.75 & 8.4 & - \\
\hline 13.01 .2020 & 7.081 & 0.130 & 0.0220 & 0.357 & 0.131 & 0.00005 & 0.0008 & 0.0031 & 0.0008 & 0.38 & 8.5 & - \\
\hline 17.01 .2020 & 7.105 & 0.131 & 0.0200 & 0.357 & 0.133 & 0.00005 & 0.0008 & 0.0060 & 0.0008 & 0.38 & 8.6 & 13.0 \\
\hline 20.01 .2020 & 6.832 & 0.121 & 0.0210 & 0.378 & 0.126 & 0.00005 & 0.0008 & 0.0033 & 0.0008 & 0,00 & 8.5 & - \\
\hline 21.01 .2020 & 7.034 & 0.163 & 0.0200 & 0.363 & 0.132 & 0.00005 & 0.0008 & 0.0066 & 0.0008 & 13.41 & 8.6 & 10.3 \\
\hline 22.01 .2020 & 6.863 & 0.121 & 0.0200 & 0.424 & 0.136 & 0.00030 & 0.0008 & 0.0053 & 0.0008 & 13.03 & 7.2 & - \\
\hline 27.01 .2020 & 6.922 & 0.137 & 0.0180 & 0.351 & 0.121 & 0.00080 & 0.0012 & 0.0037 & 0.0008 & 11.79 & 8.3 & 11.0 \\
\hline 28.01 .2020 & 7.125 & 0.152 & 0.0170 & 0.361 & 0.136 & 0.00160 & 0.0012 & 0.0091 & 0.0008 & 3.38 & 7.0 & 12.6 \\
\hline 29.01 .2020 & 6.985 & 0.131 & 0.0240 & 0.359 & 0.119 & 0.00040 & 0.0014 & 0.0042 & 0.0008 & 0.38 & 8.6 & - \\
\hline$\varnothing$ & 6.979 & 0.136 & 0.0169 & 0.361 & 0.131 & 0.00050 & 0.0009 & 0.0052 & 0.0010 & 3.58 & 7.7 & 12.1 \\
\hline
\end{tabular}

Generally Supplier No. 1 had higher content of $\mathrm{Si}, \mathrm{Ca}$ and had lower content of $\mathrm{Cu}$, than supplier No.2. Other elements had very similar content. All elements were in range of standard according to ČSN EN 1676. Values of DI were up to $1 \%$ for both suppliers. The value of modification is good for AlSi7Mg0,3. The value of Grain refinement is good too. If number is higher so modification/inoculation effect is stronger. All alloys were suitable. Supplier No. 2 had 2 melts with similar chemical composition. Difference was between content of $\mathrm{Cu}$ and Fe. Produce was without visible and major changes. Produce parameters for casting process were stayed same. Random check of casting production by X-ray was suitable (it means OK status).

\section{CONCLUSIONS}

This article is easy instructions, recommendations and inspiration how we can check raw material in foundry. Compare is showed advantage and disadvantage. In this case different size of ingot was visible in the first time. The supplier No. 2 had smaller ingots and using of them was more comfortable for melter (worker). Supplier No. 2 had non-homogeneity material, as evidence there are metallographic cuts. After remelting was chemical composition correct according to standard. During melting had not occurred any problem in process. Values of Dichte Index were generally up to $1 \%$. Very similar was result from thermal analysis for both suppliers. In production did not have different result on quality of castings and everything seemed to be fully correct. The reason for rejecting new supplier No. 1 was not found.

\section{REFERENCES}

[1] ČSN EN 1676: Aluminum and aluminum alloys - Alloyed aluminum ingots for remelting - Specification. Prague: Czech Office for Standards, Metrology and Testing. 2010.

[2] ČSN EN 1706: Aluminum and aluminum alloys - Castings - Chemical composition and mechanical properties. Prague: Czech Office for Standards, Metrology and Testing, 2010. 